\title{
Mild Traumatic Brain Injury Leads to Decreased Inhibition and a Differential Response of Calretinin Positive Interneurons in the Injured Cortex
}

\author{
Mariana Brizuela, ${ }^{*}$ Catherine A. Blizzard, ${ }^{*}$ Jyoti A. Chuckowree, Kimberley A. Pitman, \\ Kaylene M. Young, and Tracey Dickson
}

\begin{abstract}
It is clear that even mild forms of traumatic brain injury (TBI) can have lasting cognitive effects; however, the specific cellular changes responsible for the functional deficits remain poorly understood. Previous studies suggest that not all neurons respond in the same way and that changes to neuronal architecture may be subtype specific. The current study aimed to characterize the response of interneurons to TBI. To model TBI in vitro, the neurites of primary cortical neurons were transected at 15 days in vitro. In response, calretinin ${ }^{+}$interneurons underwent significant neurite remodeling around the injury site. By examining the response of pyramidal neurons, GAD67-GFP ${ }^{+}$interneurons, and calretinin ${ }^{+}$interneurons to the injury, we found that this response was specific to the calretinin ${ }^{+}$cells. To determine whether calretinin ${ }^{+}$interneurons respond in this way to a clinically relevant in vivo model of mild diffuse and focal injury, we subjected mice to the lateral fluid percussion injury model. We found that calretinin ${ }^{+}$interneuron density was unaltered by this mild injury, but consistent with our in vitro data, these neurons underwent morphological alterations in their dendrites. These alterations evolved over a $28-$ day period, and calretinin ${ }^{+}$interneurons in the injured mice had a reduction in mean dendrite length and reduced number of secondary dendrites than those in the sham-injured controls by 7 days post-injury. Further, these structural alterations were accompanied by a reduction in the frequency of miniature inhibitory post-synaptic currents in layer $\mathrm{V}$ pyramidal neurons. These data suggest that even a mild TBI can lead to an overall change in the excitatory/inhibitory balance of the cortex that may play an important role in the longer-term behavioral pathology associated with mild TBI.
\end{abstract}

Keywords: calretinin; cortex; GAD67; interneuron; mild traumatic brain injury; mouse

\section{Introduction}

$\mathbf{T}$ HE INCIDENCE OF TRAUMATIC BRAIN INJURY (TBI) is rising worldwide. ${ }^{1-3}$ Seemingly mild injuries account for approximately 80 percent of the total number of brain injuries that occur globally, and up to $25 \%$ can have persistent cognitive, behavioral and emotional consequences, with a small proportion developing post-traumatic epilepsy. ${ }^{4-9}$ The specific cellular changes that underlie the functional alterations resulting from a mild injury remain poorly understood and elucidating these mechanisms is a fundamental priority in neurotrauma research.

Accumulating evidence indicates that the brain can undergo substantial reorganization after injury. Plastic changes after injury can include alterations in synaptic strength, remodeling of axonal and dendritic arbors, and neurogenesis. ${ }^{10-16}$ The degree of plasticity occurring after injury has been classically linked to age, mode of injury, and/or the extent and region of injury. ${ }^{17-19}$ More recent studies suggest that post-injury plasticity also can be dependent on the subpopulation of neurons affected, specifically in terms of dendritic remodeling, implying that a particular response to injury can be intrinsic to a specific neuronal subtype. ${ }^{15,20}$ These results indicate that a broader understanding of the response of different subpopulations of neurons to structural injury and that the possible mechanisms underlying these responses is needed.

Inhibitory interneurons play a crucial role in neuronal plasticity during development, as increases in cortical inhibition regulate the onset and closure of critical periods. ${ }^{21-26}$ However, recent studies have indicated that changes in the inhibitory circuitry also are involved in regulating plasticity in adulthood. Interestingly, in contrast to excitatory pyramidal neurons, inhibitory interneurons seem to be highly plastic and exhibit a range of dendritic structural modifications when imaged over time in the primary visual cortex, as well as other cortical regions. ${ }^{24,27,28}$ Further, it has been suggested that morphological changes to inhibitory cell axons and 
dendrites occur after sensory deprivation and can precede and drive the changes observed in the excitatory circuitry. ${ }^{29-32}$ Despite this key evidence indicating that interneurons and inhibition may play an important role in the adult cortex, the response of these cells to cortical trauma remains relatively underexplored. However, studies examining a discreet focal injury to the somatosensory cortex indicate that subpopulations of interneurons, specifically the calretinin ${ }^{+}$interneurons, have an underappreciated potential for plasticity and remodeling following trauma. ${ }^{20}$

Calretinin ${ }^{+}$interneurons represent approximately $10-30 \%$ of the total interneuron population in the cortex. ${ }^{33}$ Even though this is a relatively small fraction of the inhibitory neurons, their unique connectivity and placement in the circuitry affords them significant control over inhibitory regulation as a whole. ${ }^{34}$ They have been described as being at the top of the interneuron hierarchy due to the fact that they preferentially regulate the activity of other interneuron populations and specifically target dendritic inhibitory interneurons to synchronize their activity. ${ }^{35,36}$ This synchronization of dendritic inhibitory cells is a crucial process to provide effective inhibitory control of excitatory pyramidal cells. ${ }^{37}$ As a result, calretinin $^{+}$interneurons influence the whole cortical inhibitory circuit and may play an important role in the sequelae of pathogenic events that follow mild brain injury. ${ }^{38}$ To determine whether this subpopulation of interneurons plays a role in the adverse outcomes that can manifest following a mild TBI, this study employed in vitro and in vivo models of brain injury. Post-injury plasticity was explored in terms of morphological changes to the dendritic arbor and the downstream consequences to the output of the cortical inhibitory network.

\section{Methods}

All experimental procedures involving animals were approved by the Animal Ethics Committee at the University of Tasmania and were performed in accordance with the Australian Code of Practice for the Care and Use of Animals for Scientific Purposes (2013) Thy1-YFP transgenic mice (B6; CBA-Tg Thy1-YFP GJrs / GfngJ) were obtained from the Jackson Laboratory. GAD67-GFP mice were developed by Prof. Nobuaki Tamamaki (Kyoto University) and were provided by Prof. John Bekkers (Australian National University). GAD67-GFP mice are maintained on a C57BL6/J background and express green fluorescent protein (GFP) in neurons expressing GAD67, one of the two genes that encode isoforms of the GABA-synthesizing enzyme glutamic acid decarboxylase. ${ }^{39,40}$ Animals were bred at the University of Tasmania and were housed in individually ventilated cages maintained at $\sim 20^{\circ} \mathrm{C}$ on a 12 -h light/dark cycle, with access to food and water ad libitum.

\section{Cell culture and axonal transection in vitro}

Primary dissociated cortical neuron cultures were prepared from mouse embryos as previously described. ${ }^{41}$ Briefly, Thy1-YFP and GAD67-GFP transgenic mice were time-mated, the pregnant females killed by $\mathrm{CO}_{2}$ exposure at 15.5 days of gestation, and the embryos removed and genotyped by exposure to a fluorescent light source. Neocortical hemispheres were dissected into $5 \mathrm{~mL}$ of Hanks Buffered Salt Solution (Thermo Fisher Scientific). Cortical tissue was dissociated by enzymatic digestion $(0.025 \%$ w/v Trypsin, $5 \mathrm{~min}, 37^{\circ} \mathrm{C}$ ), which was halted by the addition of $1 \mathrm{~mL}$ of prewarmed medium (Neurobasal supplemented with $2 \%$ v/v B27, $10 \%$ $\mathrm{v} / \mathrm{v}$ fetal calf serum, $0.5 \mathrm{mM}$ L-glutamine, $25 \mu \mathrm{M}$ glutamate and $1 \%$ streptomycin penicillin; Thermo Fisher Scientific). Tissue was dissociated with gentle trituration in $500 \mu \mathrm{L}$ of pre-warmed medium. Cell viability and concentration was assessed using trypan blue vital dye exclusion. $3.5 \times 10^{4}$ cells $/ \mathrm{mm}^{2}$ were plated per
$19 \mathrm{~mm}$ diameter glass 0 (Marienfeld). Each cover-slip was precoated with $0.001 \%$ Poly-L-lysine (Sigma-Aldrich) in $0.01 \mathrm{M}$ phosphate buffered saline (PBS; $\mathrm{pH}$ 7.0). Cultures were maintained in a $37^{\circ} \mathrm{C}$ humidified atmosphere of $5 \% \mathrm{CO}_{2}$ for up to 15 days. At 1 day in vitro (DIV), the medium was removed and replaced with serum-free growth medium (Neurobasal, $2 \% \mathrm{v} / \mathrm{v}$ B-27 supplement, $0.5 \mathrm{mM}$ L-glutamine, and $1 \%$ streptomycin penicillin; Thermo Fisher Scientific), after which time $\sim 50 \%$ of the medium was replaced every 3-4 days.

Neuronal transection was carried out using a Barkan goniotomy knife (Kaisers) on cortical cultures at 15 DIV. ${ }^{41}$ A single injury extending the full diameter of the cover-slip was made, ensuring complete axonal transection and producing a cell free lesion of $\sim 50-150 \mu \mathrm{m}$ wide. Cells were fixed for $30 \mathrm{~min}$ with $4 \%$ (w/v) paraformaldehyde (PFA) in $0.01 \mathrm{M}$ PBS at 0,4 , and $24 \mathrm{~h}$ post-injury for immunocytochemistry.

\section{In vivo fluid percussion injury model}

Adult male GAD67-GFP mice were exposed to mild TBI at 8-10 weeks of age in the form of a lateral fluid percussion injury (FPI). Animals were anesthetized with isoflurane and using a trephine, a $3 \mathrm{~mm}$ diameter craniectomy was performed $2.0 \mathrm{~mm}$ posterior and $2.5 \mathrm{~mm}$ lateral to bregma on the right hand side of the skull over the somatosensory cortex and a needle hub ( $3 \mathrm{~mm}$ inner diameter) was secured above the skull opening. One to $2 \mathrm{~h}$ later, post-craniectomy animals were re-anaesthetized with isoflurane. Once surgical anesthesia was achieved the isoflurane was withdrawn, the hub was filled with saline and mice were connected to the FPI device. Once a normal breathing pattern resumed but before sensation was restored, an injury was induced by releasing the pendulum of the FPI device onto the fluid-filled piston to induce a brief fluid pressure pulse upon the intact dura $(1.4 \pm 0.10$ atmospheres). The time taken for the mouse to regain its righting reflex was recorded. After injury the hub was removed and the animal was re-anesthetized with isoflurane and the incision sutured. Sham-injured animals received the same surgeries without receiving the injury.

To identify cells generated in the post-injury period, the thymidine analogue 5-ethynyl-2'-deoxyuridine (EdU, $0.2 \mathrm{mg} / \mathrm{mL}$; Invitrogen), was administered ad libitum via the drinking water, as previously described. ${ }^{42}$ EdU is incorporated into the DNA of dividing cells during $\mathrm{S}$ phase of the cell cycle. Mice were sacrificed at 1 day, 1 week, and 4 weeks post-injury. Mice ( $n=6$ FPI and $n=6$ sham injured per time-point) were terminally anesthetized (sodium pentobarbitone, $140 \mathrm{mg} / \mathrm{kg}$, intraperitoneally) and transcardially perfused with 4\% PFA in PBS. Brains were post-fixed in 4\% PFAPBS overnight and stored at $4{ }^{\circ} \mathrm{C}$ in PBS containing $0.1 \% \mathrm{w} / \mathrm{v}$ sodium azide (Sigma Aldrich).

For sectioning, brains were embedded in $5 \%(\mathrm{w} / \mathrm{v})$ molecular grade agarose (Bioline) dissolved in PBS. Using a Leica VT1000S vibratome (Biosystems Australia Pty Ltd, VIC Australia), 50- $\mu \mathrm{m}$ coronal sections were produced and collected as floating sections into 24 well plates (Corning Life Sciences) containing PBS sodium azide.

\section{Immunolabelling and EdU detection}

Somatosensory cortices containing the injury site were identified by referring to anatomical landmarks, such as the appearance of the lateral ventricles, the third ventricle, and the corpus callosum. Sections/cover-slips were incubated for $24 \mathrm{~h}$ at room temperature with primary antibodies that included rat anti-GFP to detect YFP or GFP (1:3000; Nacalai tesque), rabbit anti-calretinin (1:1000; Swant), and rabbit anti-activated caspase 3 (1:200; Millipore) diluted in PBS containing $0.3 \%$ triton $\mathrm{x}$ - 100 . Sections/cover-slips were washed thrice in PBS before the application of isotype- and species-specific secondary antibodies. Secondary antibodies (Alexa Fluor 594- and AlexaFluor 488-conjugated goat anti-rat and goat 
anti-rabbit IgG $\mathrm{H}+\mathrm{L}$; Invitrogen) were diluted 1:1000 in PBS and applied to sections/cover-slips for $2 \mathrm{~h}$ at room temperature. Sections/ cover-slips were washed thrice with PBS before mounting in fluorescent mounting medium (Thermo Fisher Scientific). For EdU labeling after the final immunohistochemistry washes, EdU was visualized using the AlexaFluor-647 Click-iT EdU kit (Life Technologies) as previously described. ${ }^{43}$ Coronal cortical sections from sham and FPI GAD-GFP ${ }^{+}$mice were immunostained with anticalretinin antibody to detect calretinin ${ }^{+}$interneurons. Somata and processes of GAD positive cells labeled for calretinin were identified as calretinin ${ }^{+}$.

\section{Neuronal quantification}

To perform cell counts from uninjured cultures, four images were taken from distinct regions of each cover-slip. Each timepoint $(0,4$, and $24 \mathrm{~h})$ was examined in four replicate cover-slips across three independent experiments. For cell counts of injured cultures and remodeling analysis, images were taken across the length of the scratch injury at specific distances from the injury site $(0-500 \mu \mathrm{m}, 500-1000 \mu \mathrm{m}$, and more than $1000 \mu \mathrm{m}$ from the injury). Approximately 10 images were taken from each of four replicate cover-slips across three independent experiments. To further characterize the populations of Thy1-YFP ${ }^{+}$neurons, calretinin $^{+}$interneurons and GAD67-GFP ${ }^{+}$interneurons after injury, the cell tracing software Neurolucida was utilized. Each neuron was further assessed with Neurolucida Explorer to determine the dendritic angle by performing the segment dendrite analysis (Supp. Fig. 2). For caspase immunolabeling, a minimum of four images were taken from two cover-slips that contained the injury site at every time-point analyzed $(0,4$, and $24 \mathrm{~h}$ post-injury).

Quantification of the total number of interneurons in tissue sections from GAD67-GFP mice was based on the endogenous expression of GFP enhanced by the use of an anti-GFP antibody. Quantification of the subpopulation of calretinin ${ }^{+}$interneurons was based on their expression of this calcium binding protein. Interneuron numbers was quantified within the injury site in six agematched sham-injured $(n=6)$ and FPI $(n=6)$ mice per time-point $(1,7$, and 28 days post-injury). Images were collected using an UltraVIEW spinning disk confocal microscope running Volocity Software (PerkinElmer) equipped with a Plan Apo 60x/1.20 water objective (Nikon) configured to capture $30 \mu \mathrm{m}$ Z-stacks (slices $1 \mu \mathrm{m}$ apart). The supragranular and infragranular lamina were defined as two adjacent fields containing cortical layers I-IV and VVI, respectively, and demarcated as extending from the pial surface to the gray-white matter border. To perform unbiased and inclusive quantitative analysis, ImageJ freeware was utilized for automation of cell counts. Neuronal morphology was characterized using Neurolucida software.

\section{Electrophysiological characterization of neurons ex vivo}

Thy1-YFPH or GAD67-GFP male mice received either an FPI or a sham injury at 8 weeks of age. Following cervical dislocation, mice were decapitated and their brains dissected into ice-cold sucrose solution containing: $75 \mathrm{mM}$ sucrose, $87 \mathrm{mM} \mathrm{NaCl}, 2.5 \mathrm{mM}$ $\mathrm{KCl}, 1.25 \mathrm{mM} \mathrm{NaH} \mathrm{PO}_{4}, 25 \mathrm{mM} \mathrm{NaHCO}, 7 \mathrm{mM} \mathrm{MgCl}$, and $0.95 \mathrm{mM} \mathrm{CaCl}_{2}$. Acute coronal slices $(300 \mu \mathrm{m})$ were prepared using a Leica VT1200s vibratome, and incubated at $31.7^{\circ} \mathrm{C}$ for $\geq 45 \mathrm{~min}$ in artificial cerebral spinal fluid (ACSF) containing $119 \mathrm{mM} \mathrm{NaCl}$, $1.6 \mathrm{mM} \mathrm{KCl}, 1 \mathrm{mM} \mathrm{NaH} \mathrm{PO}_{4}, 26.2 \mathrm{mM} \mathrm{NaHCO}_{3}, 1.4 \mathrm{mM} \mathrm{MgCl}_{2}$, $2.4 \mathrm{mM} \mathrm{CaCl}_{2}$, and $11 \mathrm{mM}$ glucose $(300 \pm 5 \mathrm{mosm} / \mathrm{kg})$. During recordings, slices were perfused with ACSF containing $500 \mathrm{nM}$ tetrototoxin and $1 \mathrm{mM}$ kynurenic acid, saturated with $95 \% \mathrm{O}_{2} / 5 \%$ $\mathrm{CO}_{2}$ (all Sigma Aldrich). Whole-cell recordings were obtained from layer $\mathrm{V}$ pyramidal cells within the injury site that were identified by the shape of the cell soma and presence of a long apical dendrite. Neurobiotin $(1.5 \mathrm{mg} / \mathrm{mL})$ was included in the intracellular solution and following electrophysiological analysis slices were immersion fixed in 4\% PFA-PBS for histological processing.

Recording electrodes were prepared from glass capillaries and had a resistance of 3-5 $\mathrm{M} \Omega$ when filled with an internal solution containing $120 \mathrm{mM}$ cs-methanesulfonate, $20 \mathrm{mM}$ HEPES, $0.4 \mathrm{mM}$ EGTA, $5 \mathrm{mM}$ TEA, $2 \mathrm{mM} \mathrm{MgCl} 2,2.5 \mathrm{mM} \mathrm{MgATP}$, and $0.3 \mathrm{mM}$ GTP, and set to a pH of 7.2-7.3 and an osmolarity of $280 \pm 5 \mathrm{mOsm} / \mathrm{kg}$. Recordings were collected using a HEKA patch clamp EPC800 amplifier, with a holding potential of $0 \mathrm{mV}$. Recordings were made using a gap-free protocol for $3 \mathrm{~min}$ and $10 \mathrm{sec}$, sampled at $50 \mathrm{kHz}$ and filtered at $1 \mathrm{kHz}$ using PClamp10 software (Molecular Devices). Data were not included in the analysis if the access resistance was $\geq 20 \mathrm{M} \Omega$, or if the access resistance changed by $\geq 10 \%$ during the course of the recording. There was no significance difference in access resistance between the sham and FPI groups $(p>0.05)$. Data collection was carried out only if the recordings were stable for more than 3 minutes. Mini inhibitory post-synaptic currents (mIPSCs) were defined as having an amplitude $\geq 8 \mathrm{pA}$, and were analyzed using the MiniAnalysis60 program (Synaptosoft, Decateur). Post-recording, the patch electrode was removed from the neuron, which was later identified by the detection of Neurobiotin with an Alexa Fluor 594 conjugated anti-streptavidin antibody (Molecular Probes; $0.1 \%$ triton-X-diluent detergent), to confirm that recorded cells were indeed layer $\mathrm{V}$ pyramidal neurons in the injury site.

\section{Statistical analysis}

All data was analyzed using a two-way analysis of variance followed by Bonferroni post hoc tests (GraphPad Prism, version 6.0) for group and regional comparisons. Average values were expressed as means \pm standard error of the mean. For electrophysiological comparisons, two-tailed $t$-tests were performed. A $p$ value $<0.05$ was considered significant.

\section{Results}

\section{Calretinin ${ }^{+}$interneurons remodel their neurites after injury in vitro}

Neurons derived from Thy1-YFP transgenic mice were grown for 15 DIV before being subjected to neuronal transection and fixed at 0,4 , and $24 \mathrm{~h}$ post-injury. Immunolabeling with antibodies to detect the calcium binding protein calretinin and YFP identified calretinin ${ }^{+}$interneurons and pyramidal neurons, respectively. Neurites labeled with calretinin or YFP were classified as projecting "away" from the injury site if they formed an angle of $0^{\circ}$ to $180^{\circ}$ with the injury site or "towards" the injury site if they formed an angle of $180^{\circ}$ to $360^{\circ}$ with the injury site. Neurites were examined at increasing distances from the injury site, and at different time-points post-injury (Fig. $1 \mathrm{~A}-\mathrm{D}$ ). The orientation of individual neurites for each neuron subtype was determined and the percentage of neurites that were projecting away or towards the injury site was calculated.

At $4 \mathrm{~h}$ post-injury, $\mathrm{YFP}^{+}$neurons located within $500 \mu \mathrm{m}$ of the injury site did not appear to alter the orientation of their neurites relative to uninjured controls (Fig. 1F). However, the orientation of calretinin $^{+}$neurites was altered, with the proportion of neurites projecting away from the injury being significantly increased (Fig. 1F). When we performed the same analysis at 0 and $24 \mathrm{~h}$ postinjury, we did not detect any significant change in the orientation of $\mathrm{YFP}^{+}$or calretinin + neurites on injured relative to control cover-slips (Fig. 1E, 1G). Additionally, neurite orientation was unaltered at distances great than $500 \mu \mathrm{m}$ from the injury site (Supplementary Fig. 1; see online supplementary material at www.liebertpub.com). 

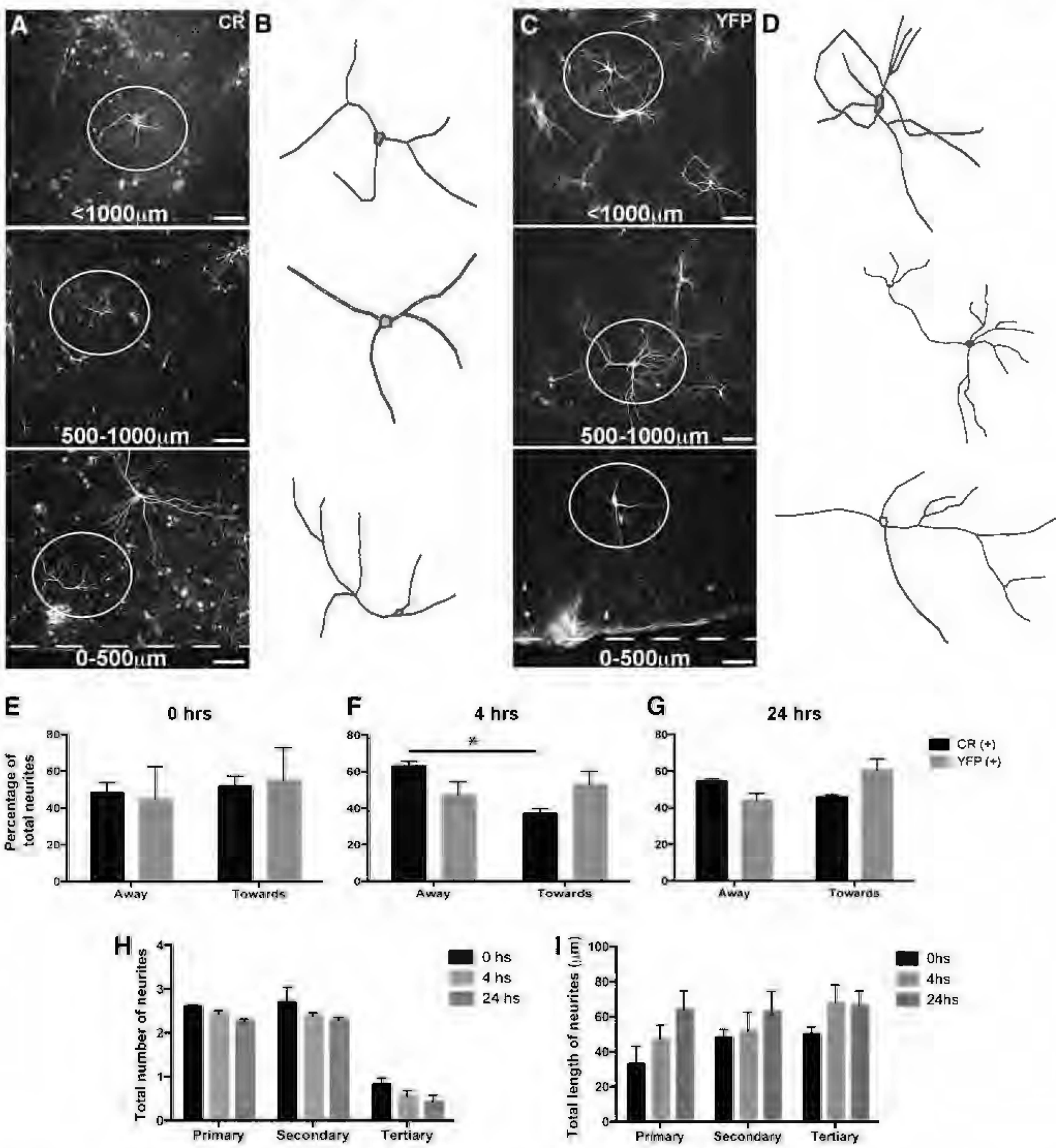

FIG. 1. Post-injury neurite remodeling of calretinin+ interneurons at 15 days in vitro (A-D) Representative imgges (A and C) and Neurolucida tracings (B and D) of calretinint interneurons (A,B) and YFP pyramidal jneurons (CD) at 4h post-injury at increasing distances from the injury site. (E-G) The percentage of calretinin+ or YFP+ neurites that wene directed away or towards the injury within $0-500 \mu \mathrm{m}$ of the injury site at $0 \mathrm{~h}(\mathrm{~B}), 4 \mathrm{~h}(\mathrm{~F})$, and $24 \mathrm{~h}(\mathrm{G})$. At $4 \mathrm{~h}$, there was a significant difference between the percentage of neuritis directed awhy and toward the injury site. (H) There was no difference in the total number of neurites at 0,4 , and $24 \mathrm{~h}$. (I) There was no difference in the total length of neurites at 0,4 , and $24 \mathrm{~h}$. Two-way analyais of variance followed by Bonferconi teat. Daila are presented as meantstandard error of the mean. Scale bar $=50 \mu \mathrm{m}$, Dotted line indicates edge of injury site. CR, calretinin.

Quantification of the total number and length of primary, secondary,

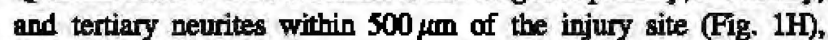
confirmed that the change in orientation of calretinin ${ }^{+}$neurites at $4 \mathrm{~h}$ post-injury did not result from a change in the total number or length of neurites at any time-point investigated.
To determine whether remodeling neurites awray from in injury site is a plasticity response common to all interneurons or is a response unique to calretinin ${ }^{+}$intermeurons, cultures derived from GAD67-GFP mice were grown to relative maturity in vitro (15 DIV) and subjected to a transection or sham injury. Cultures were 
fixed at $4 \mathrm{~h}$ post-injury and processed to detect GFP and calretinin Interneurons that were either GAD67-GFP alone or calretinin ${ }^{+} /$ GAD67-GFP' were analyzed as previously described to determine their capacity for neurite remodeling after injury. Only calretinin ${ }^{+} /$ GAD67-GFP' intemeurons remodeled their neurites away from the injury site (Fig. 2A, 2B; $p=0.005$ ). By contragt, the neurite trajectories of GAD67-GFP interneurous that pere not calretinin ${ }^{+}$ were not aignificantly changed in the injury relative to control conditions (Fig. 2B).

To investigate neuronal viability after injury, we quantified the proportion of calretinin ${ }^{+}$interneurons relative to the total number of GAD67-GFP' interneurons in control and injured cultures. The proportion of calretinin ${ }^{+}$interneurons increased relative to the total mumber of GAD67-GFP' interneurons between 9 to 12 DIV, increasing from $\sim 15 \%$ at 9 DIV to $\sim 30 \%$ at 12 DIV. However, by 15 DIV the proportion of GAD67-GFP" inferneurons that expressed calretinin stahilized al $\sim 27 \%$. When the proportion GAD67-GFP' interneurons that expressed calretinin was examined within $500 \mu \mathrm{m}$ of the injury aite at 0,4 , and $24 \mathrm{~h}$ post-injury, there was no significant difference between injured and control cultures (Fig. 3A, 3B), grosaly indicating that this injury wag not affecting internearon number.

To further investigate the viability of calretinin ${ }^{+}$neurons "close" to the injury site, immunocytochemistry to detect activaled caspase 3 was performed. Caspase 3 is a protease invalved in initiating the neuronal cell death cascade and is therefore an important marker of cells entering the apoptotic-signaling pethway. ${ }^{44}$ GAD67-GFP ${ }^{+}$ interneurons in control or injured cultures did not express caspase 3, indicating that these interneurons pere not undergoing programmed cell death (Fig. 3C, 3D). These results indicate that there was no significant death of interneurons in response to the transection injury.

\section{Mild $78 \mathrm{I}$ induces cell proliteration but not neurogenesia}

To investigate the possibility that calretinin ${ }^{+}$intemeurons were tifferentially vulnerable to injury in vivo, we used a fluid percussion device to deliver a unilateral mild injury over the somatosensory

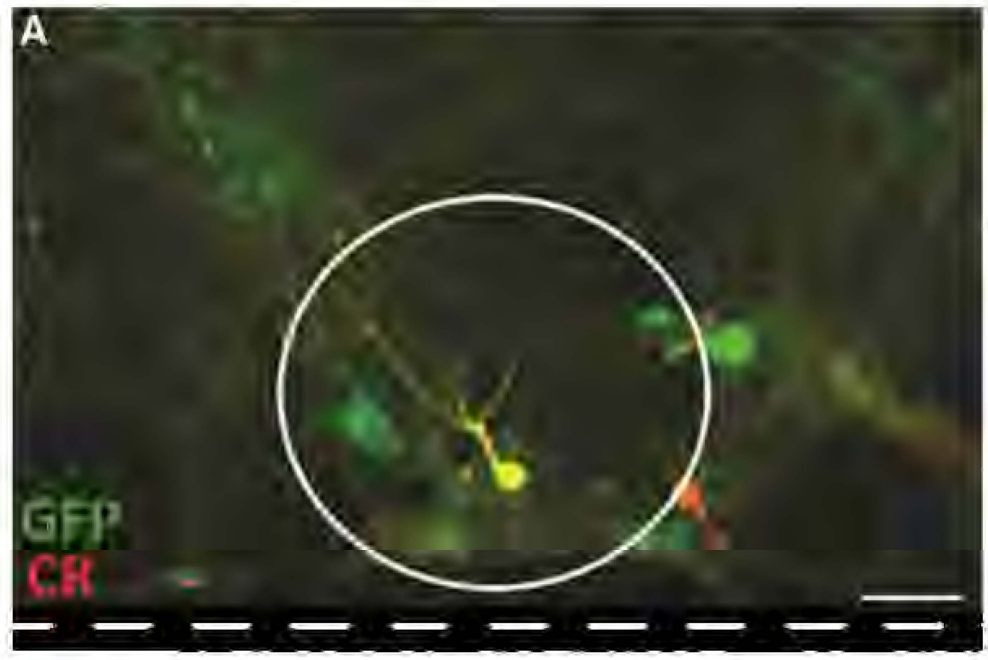

B

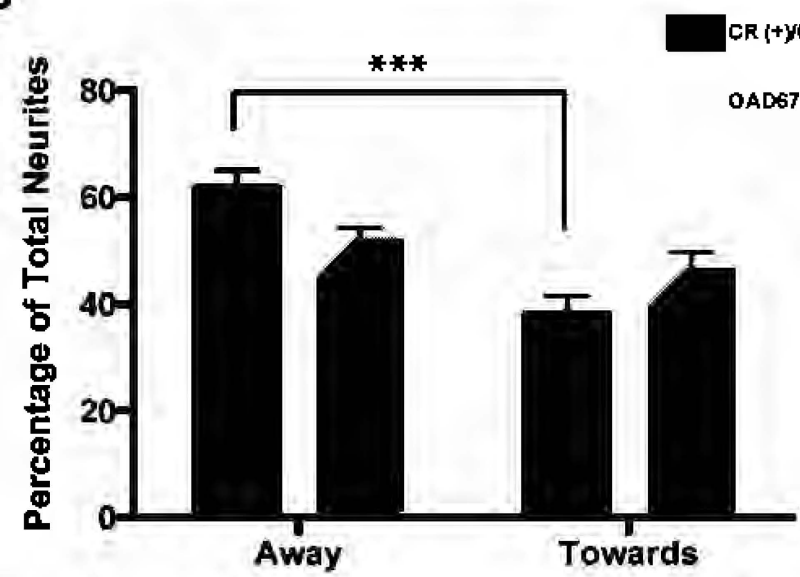

FIG. 2 Post-injury neurite remodeling is specific to the calretinin+ subpopulation. (A) Representative image of calretinin + (red) and GAD67-GFP+ (green) intermeuron at $4 \mathrm{~h}$ post-injury at 0-500 $\mu \mathrm{m}$ from the injury site. (B) The percentage of GAD67-GFP4 or calretinin+/ GAD67-GFP+ labeled neurites that orientated away or towards the injury at 0-500 $\mu$ m from the injury gite. There was a significant difference between the proportion of calretinin+/GAD67-GFP+ interneurons directed away and toward the injury site at $4 \mathrm{~h}$ post-injury (B; $p=0.005$ ). There was no significant difference in the GAD67-GFP+ neurites at $4 \mathrm{~h}$ post-injury. Scale bar $=40 \mu \mathrm{m}$. Dotted line indicates edge of injury site. CR, calretinin. Color image is available online at www liebertpub.com/neu 

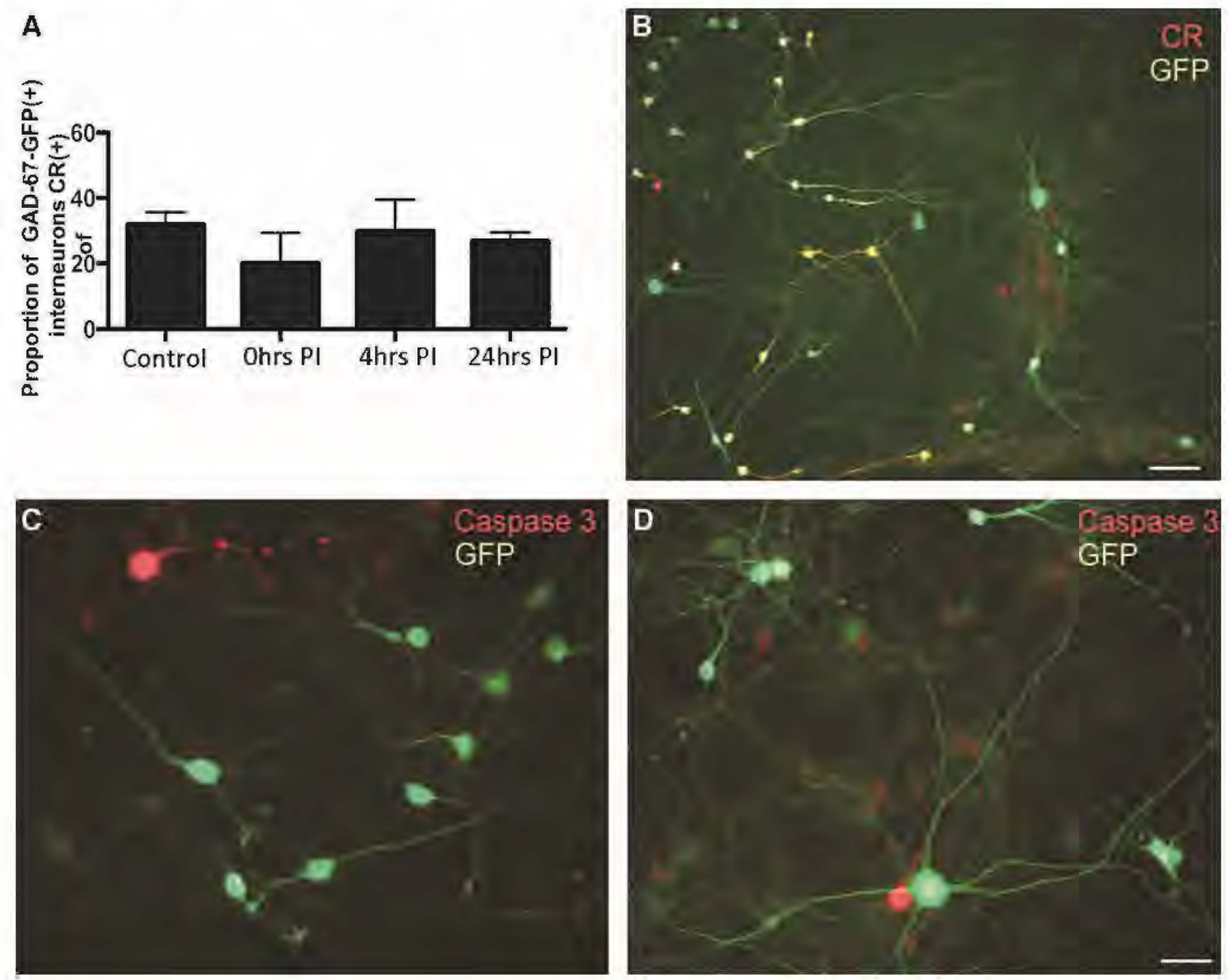

FIG. 3. Calretinin+ interneurcm viebility over $24 \mathrm{~h}$ post newile injury. (A) There were no significant differences foumd in the proportion of calretinin+/GAD67-GFP+ interneurons from the total number of GAD67-GFP+ interneurons at any of the post-injury time-points analyzed, compared with control cultures. (B) Representative image of calretinin+/GAD67-GFP+ interneurons at $4 \mathrm{~h}$ postinjury. (C, D) Representative images of immmnolabeling with anti-activated caspase 3 antibody and anti-GFP in control (C) and injured (D) cortical cultures at $4 \mathrm{~h}$ post-injury. Scale bar $(B)=50 \mu \mathrm{m},(C)$ and $(D)=30 \mu \mathrm{m}$. CR, calretinin. Color image is available online at www liebertpub.com/neu

cortex of GAD67-GFP mice. We confirmed that our protocol delivered a mild injury, as the mice showed a short post-injury righting time (between 2-4 min) and did not experience mortality after injury (Table 1). ${ }^{45}$ The mild FPI incuced a transient behavioral euppression of the righting reflex in all injured animals of $2.60 \pm 0.58 \mathrm{~min}$, which was significantly longer than sham-injured animals $(0.15 \pm 0.10 \mathrm{~min} ; p<0.001)$. There were no significant differences in age or weight between the sham-injured and FPI mice at any time post-injury. This mild unilateral fluid percussion injury did not result in contusion, intraparenchymal hemonhage, or notable cortical loss (Fig. 4A). In conclusion, the parameters measured were consintent with the delivery of a mild injury to the cortex ${ }^{4 S}$

Tarle 1. Parameters Mrastred in the Gad67-GFP Mice Exposed to Lateral FPI

\begin{tabular}{|c|c|c|c|c|c|c|}
\hline & \multicolumn{2}{|c|}{$I$ day $P I$} & \multicolumn{2}{|c|}{7 days $P I$} & \multicolumn{2}{|c|}{28 days $P I$} \\
\hline & $\begin{array}{l}\text { Sham } \\
\mathrm{n}=6\end{array}$ & $\begin{array}{l}F P I \\
\mathrm{n}=6\end{array}$ & $\begin{array}{l}\text { Shom } \\
n=6\end{array}$ & $\begin{array}{c}F P I \\
\mathrm{n}=6\end{array}$ & $\begin{array}{l}\text { Shan } \\
\mathrm{n}=6\end{array}$ & $\begin{array}{l}F P I \\
\square=6\end{array}$ \\
\hline $\begin{array}{l}\text { Age (weeks) } \\
\text { Weight (g) } \\
\text { FPI (atm) } \\
\text { Righting time (min) }\end{array}$ & $\begin{array}{c}11.3 \pm 0.88 \\
28.6 \pm 0.9 \\
\text { NA } \\
0.2 \pm 0.1\end{array}$ & $\begin{array}{l}9.6 \pm 0.71 \\
27.3 \pm 1.4 \\
1.44 \pm 0.10 \\
2.16 \pm 0.53\end{array}$ & $\begin{array}{c}11.2 \pm 0.48 \\
29.2 \pm 0.6 \\
\text { NA } \\
0.1 \pm 0.1\end{array}$ & $\begin{array}{l}11.3 \pm 0.56 \\
29.9 \pm 0.9 \\
1.37 \pm 0.12 \\
2.67 \pm 0.61\end{array}$ & $\begin{array}{c}12.7 \pm 0.21 \\
26.0 \pm 0.78 \\
\text { NA } \\
0.1 \pm 0.1\end{array}$ & $\begin{array}{l}12.5 \pm 0.48 \\
26.2 \pm 1.1 \\
1.39 \pm 0.15 \\
2.04 \pm 0.30^{*}\end{array}$ \\
\hline
\end{tabular}

FPL, thuid perctution injury: PL, post-injury. 

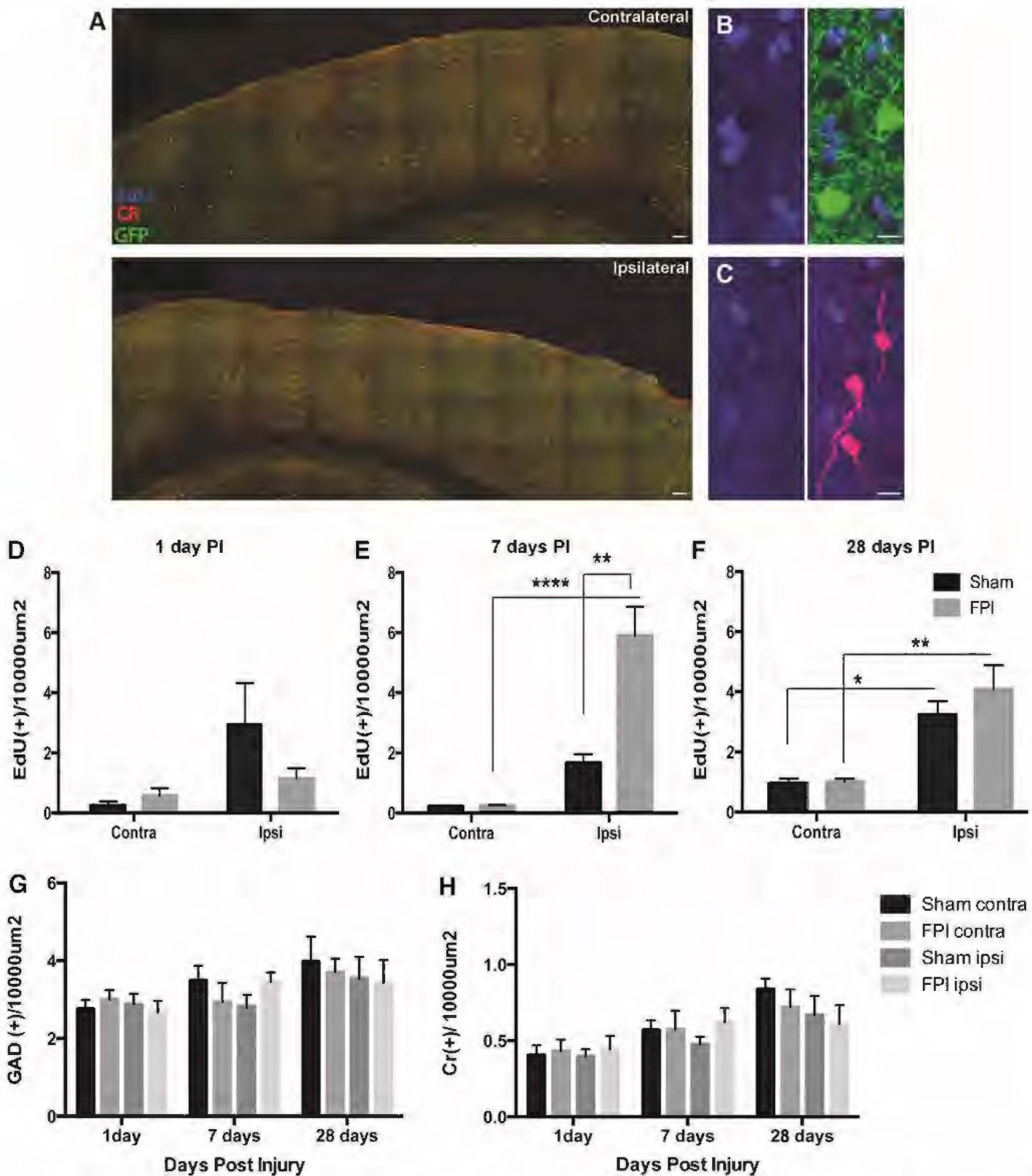

Sham contra FPI contra Sham ipsi FPl ipsi

FIG. 4 Analyris of newly produced cells after mild TBI indicate no interneuron neurogenesis. In order to visualize newly produced cells GAD67-GFP mice received EdU vin the drinking water after injury for 1 day, 7 days or 28 days to label dividing cells. (A) Immunolabeling for calretinin, EdU and GFP contralateral and ipsilaleral to the injury site. Mild laleral fluid percussion injury did not result in contusion, intraparenchymal hemorrhage or cortical loss. (B, C) Representative images of the ipsilateral GAD67-GFP cortex after mild FPI injury immunolabeled for $\mathrm{EdU}^{+}$(B, blue) and GAD67-GFP (B, green) and labelled for $\mathrm{EdU}^{+}$(C, blue) and calretinin ${ }^{+}(\mathrm{C}$, red) cells. (D) There was no significant increase of EdU' cells at 1 day post-injury. (E) There was a significant increase in the number of EdU ${ }^{+}$cells at 7 days post-injury in the ipsilateral cortex of FPI injured mice compared to the contralateral side and the ipsilateral cortex of Sham mice (E, p < 0.0001, p <0.001). (F) At 28 days port-injury there was a significant inctease in the number of EdU ${ }^{+}$cells in the ipsilateral cortex of Sham and FI mice in respect to the contralateral cortex $(p<0.05, p<0.01$ respectively). (G) There were no significant differences found in the total number of GAD67-GFP' intemeurons found between the Sham and FPI injured mice at different time points post-injury, ipsilateral or contralnteral to the injury site. (H) There were no significant differences found in the total number of calnetimin ${ }^{+}$interneurons found between the Sham and FPI injured mice at different time points pont-injury, ipsilateral ar contralateral to the injury aite. Data are presented as mean $\pm S E M$. One-way ANOVA, followred by Bonferroni test. Scale A $=100 \mu m$; $B$ and $C=30 \mu m$. Color image is available online at www.liebertpub.com/neu 
To investigate a potential induction of neurogenesis following the mild injury, EdU was administered via the drinking water to sham-injured and FPI mice for 1, 7, or 28 days post-injury. Coronal brain sections were processed to detect GFP, calretinin, and EdU, and no newly generated GAD67-GFP ${ }^{+}$interneurons or calretinin ${ }^{+}$ interneurons were detected in the cortex ipsilateral or contralateral to the injury site of FPI or sham-injured mice (Fig. 4B, 4C). The number of $\mathrm{EdU}^{+}$cells was quantified in the ipsilateral and contralateral cortex of sham-injured and FPI mice (Fig. 4D-F), and there was no significant change in the number of EdU-labeled cells present in the somatosensory cortex at 1 day post-injury ipsilateral or contralateral to the injury site when comparing sham-injured or FPI mice (Fig. 4D). However, the number of $\mathrm{EdU}^{+}$cells was significantly elevated in the ipsilateral cortex of FPI mice relative to sham-injured mice, and relative to the contralateral cortex 7 days (Fig. 4E) and 28 days post-injury (Fig. 4F). These data indicate that a mild FPI triggers a proliferative response, presumably from local glial populations, in the weeks to months following the impact. Of particular importance for this study, a mild FPI did not trigger interneuron addition to the injury site. There were no newly generated $\mathrm{GFP}^{+}$interneurons or $\mathrm{CR}^{+}$interneurons detected in the injured cortex ipsilateral or contralateral to the injury site in the FPI or sham animals at any of the post-injury time-points analyzed ( 0 $\mathrm{GFP}^{+} \mathrm{EdU}^{+}$cells from a minimum of $200 \mathrm{GFP}^{+}$cells per section per animal and $0 \mathrm{CR}^{+} \mathrm{EdU}^{+}$cells from a minimum of $25 \mathrm{CR}^{+}$cells per section per animal).

To determine whether mild TBI had an effect on interneuron viability, the total number of $\mathrm{GFP}^{+}$interneurons was examined in the cortex of GAD67-GFP FPI and sham-injured mice at 1, 7, and 28 days post-injury (Fig. 4G). Our mild FPI did not affect the total number of interneurons present in the ipsilateral or contralateral somatosensory cortex at 1,7 , or 28 days post-injury (Fig. $4 \mathrm{G}$; $p=0.85$ ). Further, as subpopulations of interneurons populate specific cortical layers, we examined the total number of interneurons in different layers of the cortex, and found that the injury did not influence the number of interneurons present in the supragranular (layers I-IV; $p=0.77$ ) or infragranular layers (layers V, VI; $p=0.66$ ) (Supplementary Fig. 1). These results suggest that interneuron number is not altered in vivo by a mild TBI.

To build on our earlier results indicating that calretinin ${ }^{+}$interneurons had a cell type specific response to injury in vitro, we quantified the number of calretinin ${ }^{+}$interneurons in the cortex of GAD67-GFP sham-injured and FPI mice at 1,7 , and 28 days postinjury (Fig. 4H). Quantification of the total number of calretinin interneurons demonstrated that mild injury had no effect on the total number of calretinin ${ }^{+}$interneurons ipsilateral or contralateral to the injury site at any of the post-injury time-points analyzed, compared with sham-injured mice (Fig. $4 \mathrm{H} ; p=0.32$ ). There also was no significant change in the number of calretinin ${ }^{+}$interneurons in the supragranular (layers I-IV; $p=0.55$ ) or infragranular layers (layers V, VI; $p=0.50$ ) of the cortex at any of the post-injury timepoints examined (data not shown). These data indicate that mild TBI does not lead to a loss of calretinin ${ }^{+}$interneurons or a change in their cortical distribution.

\section{Mild TBI induces morphological changes in calretinin ${ }^{+}$interneurons}

Calretinin ${ }^{+}$interneurons responded to in vitro transection injury by rearranging their dendritic arbors away from the injury site (Fig. 1). To determine whether calretinin ${ }^{+}$interneurons respond to a mild diffuse and focal injury in vivo in a similar fashion, we ana- lyzed the dendritic arbor of calretinin ${ }^{+}$interneurons ipsilateral and contralateral to the injury site at 7 and 28 days post-injury, comparing sham-injured and FPI mice (Fig. 5A, 5B).

By 7 days post-injury, the total length of the dendritic arbor of calretinin $^{+}$interneurons located ipsilateral to the injury, was reduced in the somatosensory cortex of GAD-67-GFP ${ }^{+}$FPI mice relative to sham-injured controls (Fig. 5C; 64 neurons analyzed per mouse, $n=6$ mice per group, two-way analysis of variance [ANOVA]; $p=0.004)$. By 28 days post-injury, there was no longer a significant difference in the total length of the dendritic arbor of calretinin $^{+}$interneurons in the ipsilateral cortex of sham-injured and FPI mice (Fig. 5D, 5C). Additionally, no difference was detected when comparing the total arbor length of calretinin ${ }^{+}$interneurons on the contralateral side of sham-injured or FPI mice at 7 or 28 days post-injury (Fig 5C, 5D; two-way ANOVA; $p=0.22$ ).

We next compared the number of dendritic branches elaborated by calretinin ${ }^{+}$interneurons located ipsilateral to the injury site, in GAD-67-GFP ${ }^{+}$sham-injured and FPI mice at different time-points post-injury. This analysis indicated that calretinin ${ }^{+}$interneurons respond to a mild TBI by decreasing their dendritic arbor complexity over the first 7 days post-injury (Fig. 5E). The reduction in dendritic complexity detected at 7 days post-injury was the result of calretinin $^{+}$interneurons located ipsilateral to the FPI losing their secondary dendrites. However, this was a transient plasticity response, with the neurons elaborating new secondary dendrites by 28 days post-injury (Fig 5F; two-way ANOVA; $p=0.09$ ). There were no differences found in soma size or the length of individual dendritic branches for calretinin ${ }^{+}$interneurons in the injured cortex, compared with the sham-injured cortex, at any of the time-points analyzed (Supplementary Fig. 1).

\section{Reduced synaptic inhibition in layer $V$ pyramidal neurons after mild TBI}

To determine whether the injury-induced alterations in the dendritic arbor of calretinin ${ }^{+}$interneurons altered inhibitory signaling in the cortex, we performed whole-cell patch clamp analysis of layer V pyramidal neurons in acute slices from Thy1-YFP-H sham-injured and FPI mice. Upon patching, each YFP $^{+}$pyramidal neuron was filled with neurobiotin, which allowed us to histologically confirm its location in layer $\mathrm{V}$ of the injured somatosensory cortex (Fig. 6A, 6B). There was no difference in the capacitance of pyramidal neurons in the cortex of FPI and sham-injured mice (sham $58.5 \mathrm{pF} \pm 9.2 \mathrm{pF}$, FPI $48.1 \mathrm{pF} \pm 3.5 \mathrm{pF} ; p=0.268$, two-tailed $t$-test). The average amplitude (Fig $6 \mathrm{C}, 6 \mathrm{D}$; sham $12.7 \mathrm{pA} \pm 0.8 \mathrm{pA}$, FPI $13.5 \mathrm{pA} \pm 0.7 \mathrm{pA} ; p=0.491$, two-tailed $t$-test), rise time (Fig. 6F; sham $4.33 \mathrm{msec} \pm 0.64 \mathrm{msec}$, FPI $4.78 \mathrm{msec} \pm 0.71 \mathrm{msec}$, $p=0.67$, two-tailed $t$-test) and decay time (Fig. 6G; sham $7.38 \mathrm{msec}$ $\pm 0.95 \mathrm{msec}$, FPI $13.32 \mathrm{msec} \pm 2.74 \mathrm{msec}, p=0.14$, two-tailed $t$-test) of miniature inhibitory post-synaptic currents (mIPSCs) recorded from layer $\mathrm{V}$ pyramidal neurons located in the cortex of shaminjured and FPI mice at 7 days post-injury was equivalent, indicating that there were no changes to post-synaptic $\mathrm{GABA}_{\mathrm{A}}$ receptors. The mean rising time for sham and FPI was $4.41 \mathrm{msec}$ but most neurons had a mIPSC rising time between $2-4 \mathrm{msec}(n=15$; sham and FPI), fewer neurons had a slower rising time greater than $4 \mathrm{msec}$ $(n=4$; sham and FPI)). The neurons with a rise time of greater than $4 \mathrm{msec}$ had no difference in capacitance or access resistance when separated from the total population and hence did not stratify any criteria for exclusion. The fast mIPSCs could represent currents originating from synapses on the soma and proximal dendrites, whereas the slow mIPSCs could be generated in synapses located 

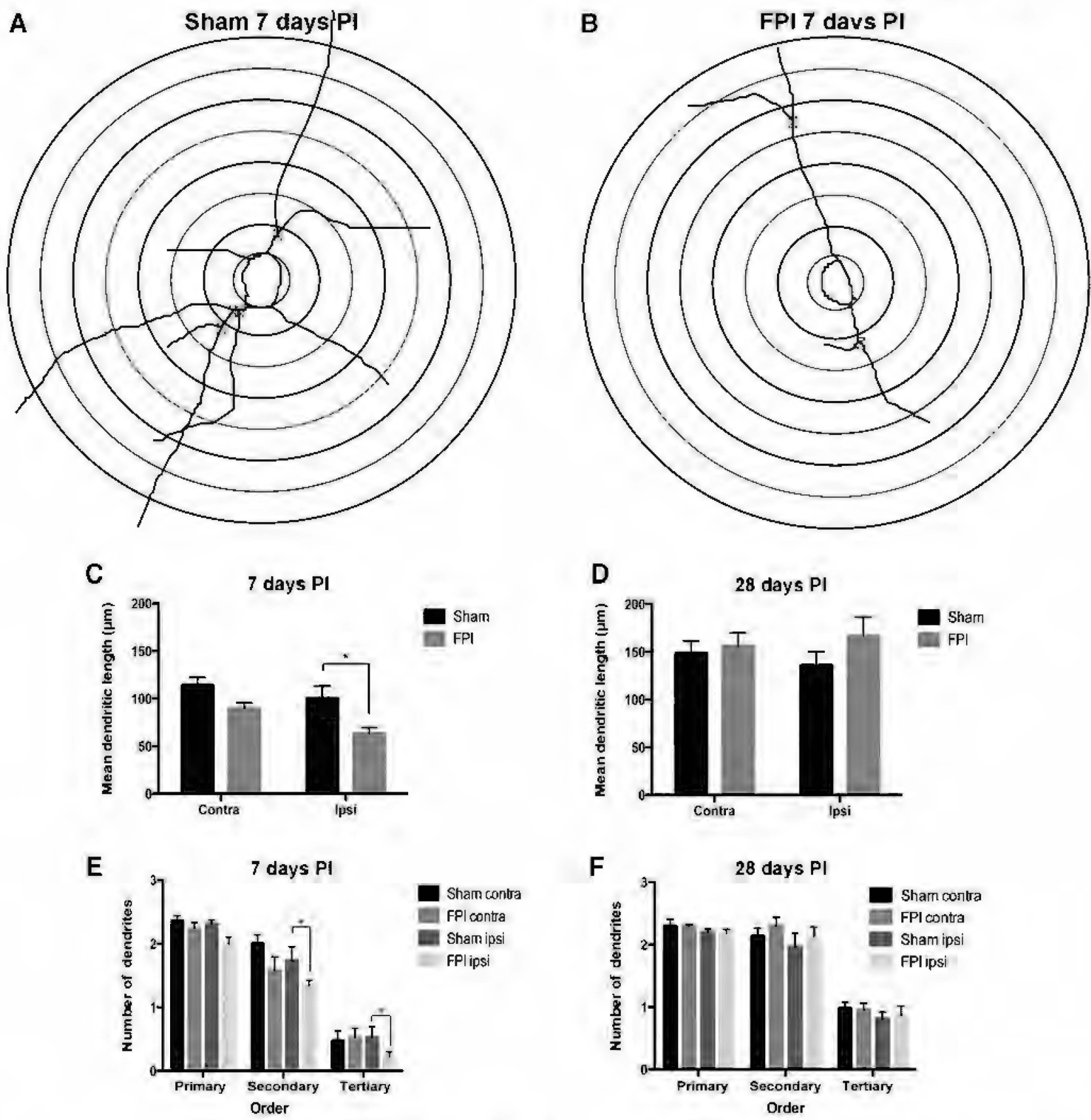

FIG. 5. Calretinin interneurons dendritic arbor complexaty analysis at 7 and 28 days after mild TBI. Calretinin+ interneurons were traced using Neurolucida software in order to investigate their dendritic morphology at 7 and 28 days post-injury. (A, B) Representative images of calretinin+ interneurons in the ipsilateral cortex of fluid percussion injury (FPI; A) and sham (B) mice at 7 days post-injury. Each concentric circle represents $10 \mu \mathrm{m}$ from the cell soms (C) There was significant decrease in total dendritic length in calnetinint intermeurons found in the ipsilateral side in FPI-injured mice, compared with aham mice at 7 days post-injury $(p<0.05)$. (D) There was no significant decrease in total dendritic length in calretinin+ intemeurons found in the ipsilaleral side in FPI injured mice, conmpared with sham mice at 28 days post-injury $(p<0,05)$. (E, F) The number of primary, secondary and tertiary dendrites was evaluated at 7 (E) and 28 days post-injury (F). (F) There was a significant decrease in the number of secondary and tertiary order processes in calretinint intermeurons found in the ipsilateral side of FPI-injured mice, compared with the ipsilateral side of sham animsls (D; $p<0.05)$. (C-F) Data presented as mean \pm standard error of the mean. Two-way analysis of variance, followed by Bonferroni test. 

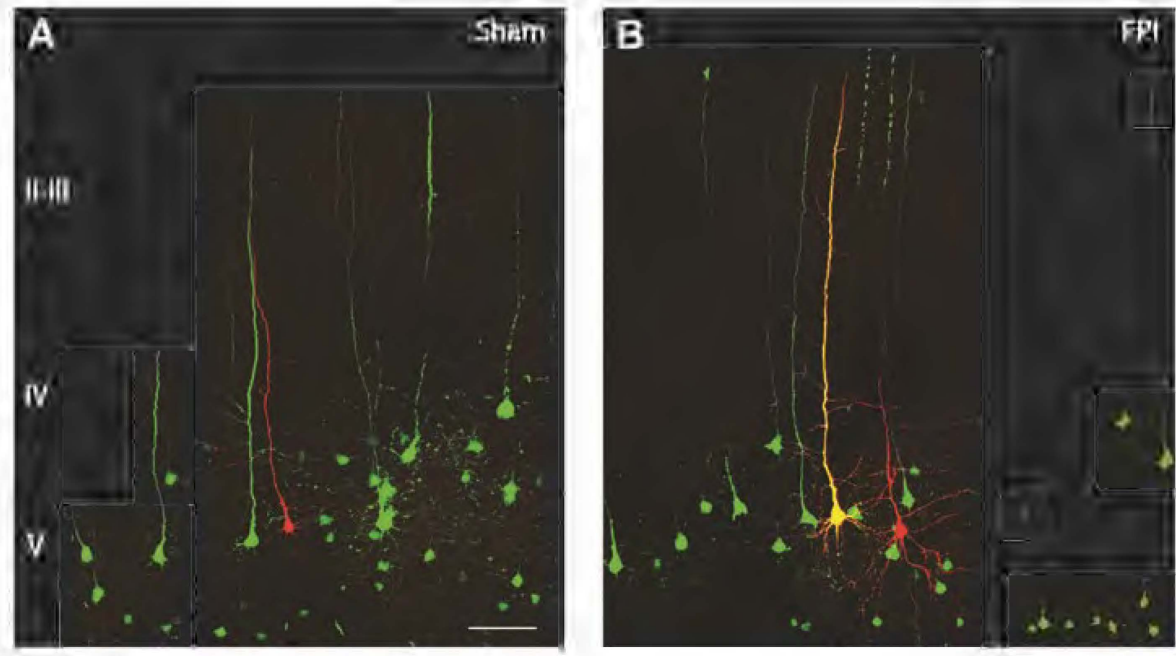

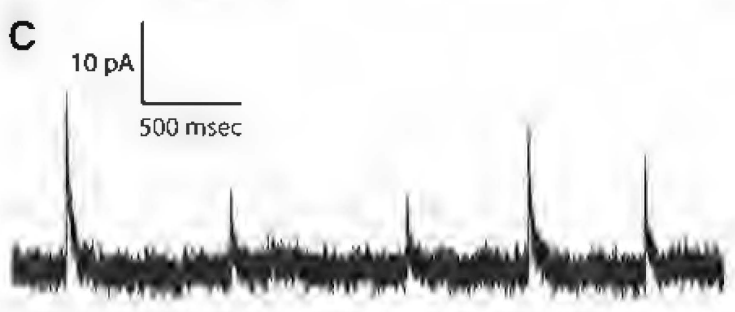

Sham 7 days PI
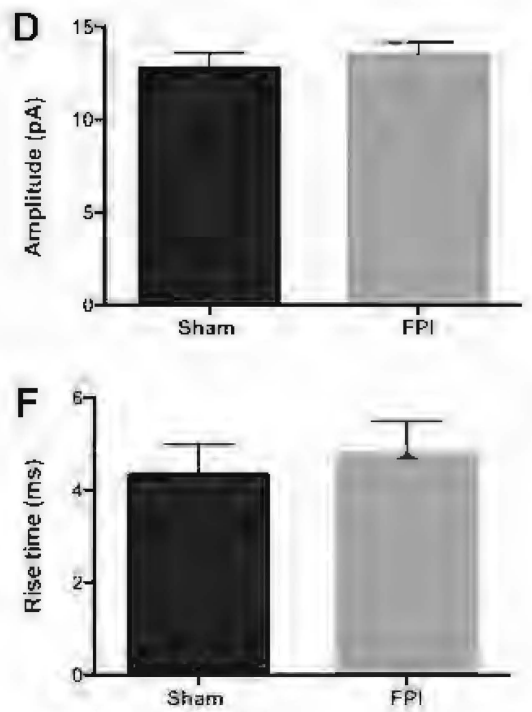

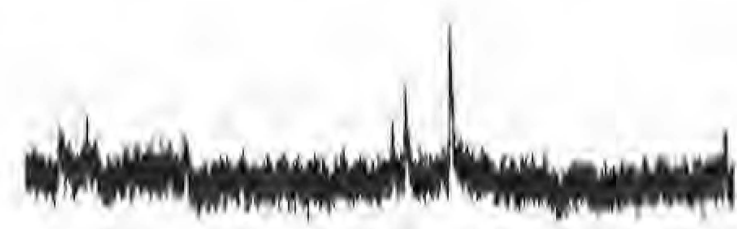

FPI 7 days PI
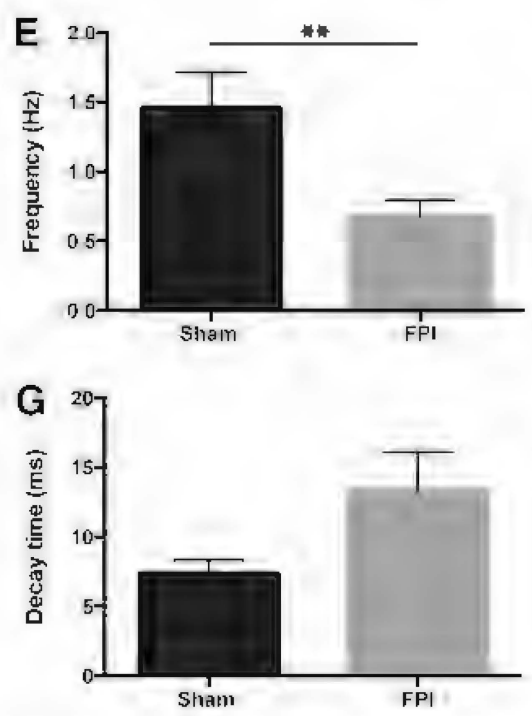

FIG. 6. Analysis of symaptic inhibition in layer $V$ pyramidal neurons after mild traumatic brain injury. Whole-cell patch clamp recordings from layer $V$ pyramidal neurons from sham and FPl-injured mice were taken. Representative images of layer V Neurobiotin filled neuroas after whole cell patch clamping in sham (A) and fluid percussion injury (FPD) injured (B) cortical slices. Examples of mini inhibitory post-synaptic currents (mIPSCs) recorded in pyramidal neurons from sham and FPI-injured mice (C). There were no significant differences found in mIPSCs amplitude (bham 12.74 $\pm 0.68 \mathrm{pA}$; FPI $13.50 \pm 0.67 \mathrm{pA}$ ) (D), rise time (sham $4.34 \pm 0.64 \mathrm{mgex}$;

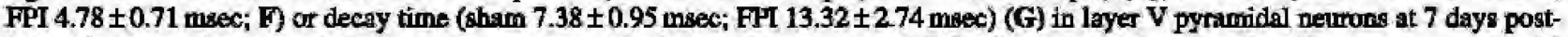
injury between sham and FPI mice. There pas a significant decrease in mIPSCs frequency (sham $[n=8$ cells from five animals] $1,46 \pm 0.25 \mathrm{~Hz}$, FPI $[n=12$ cells from eight animals] $0.68 \pm 0.12 \mathrm{~Hz} ; p<0.01$ ). Paired $t$-test. Scale bar $=100 \mu m$. Color image is avnilable online at www liebertpub.comheu 
more distally on the dendrites. However, there was a significant decrease in the frequency of mIPSCs from $1.46 \pm 0.26 \mathrm{~Hz}$ to $0.68 \pm 0.12 \mathrm{~Hz}$ (Fig. $6 \mathrm{E} ; p<0.0061$, two-tailed $t$-test), indicating that the pyramidal neurons in the somatosensory cortex of injured mice received significantly fewer inhibitory synaptic inputs compared to sham-injured controls.

\section{Discussion}

A majority of cases of TBI are mild injuries that involve only brief loss of consciousness. ${ }^{46,47}$ Although the deficits produced by mild TBI are frequently subtle, memory, affective, and executive dysfunction can nevertheless emerge and cause substantial impairment and life disruption. ${ }^{48,49}$ These impairments arise despite the absence of clear structural damage, suggesting the resultant deficits are not a direct result of cortical loss and that adaptive and maladaptive plasticity alterations are at play. ${ }^{50} \mathrm{It}$ is well established that after a traumatic injury to the brain, neurons can respond and attempt regeneration through the spontaneous rearrangement of the affected network in the form of compensatory morphological or structural plasticity; however, the role that neuronal plasticity plays in mild forms of trauma is not clear. ${ }^{20,51}$ The current study utilized two contrasting models of injury (in vivo mild diffuse injury vs. in vitro single complete neurite transection in relatively mature neurons) to investigate the response of interneurons, focusing on calretinin $^{+}$interneurons, to injury. Mild injuries in vivo were confirmed by the lack of clear structural damage, absence of postinjury mortality, and short time required for mice to regain their righting reflex post-TBI. ${ }^{45,52}$ Our investigations demonstrated that following mild injury, calretinin ${ }^{+}$interneurons have the capacity for neurite plasticity around the injury site and that this plasticity corresponded to decreased inhibitory input in pyramidal neurons. Further, our investigations indicate that the response of the calre$\operatorname{tinin}^{+}$interneurons is replicated in different models of injury, suggesting this response is a conserved mechanism of these cells and may be generalizable to the array of varying forms of trauma that can occur. Understanding the aberrant alterations in excitability in the brain following trauma will aid in unraveling why even mild forms of injury can have such lasting effects cognitively.

Lateral FPI is a well-characterized model of brain injury that produces both focal and diffuse effects, including the generation of new cells. ${ }^{53-58}$ Therefore, cell proliferation in the cortex was evaluated as the presence of newly generated $\mathrm{EdU}^{+}$cells following mild FPI. It was determined that mild FPI induces cell proliferation within the injury site but not in other regions of the cortex, including the contralateral hemisphere. Several studies have observed neurogenesis in rodents in response to moderate-to-severe traumatic brain injury. ${ }^{59-63}$ However, most studies have indicated that neurogenesis does not lead to neuronal replacement in the cortex. $^{20,64}$ Since the focus of the current study is the inhibitory network, the presence of newly generated cortical interneurons was evaluated. There was no induction of interneuron neurogenesis after injury indicated by the lack of either $\mathrm{GFP}^{+}$or calretinin ${ }^{+}$ neurons positive for EdU in the cortex.

Several studies have reported a deficit in GABAergic activity and loss of GABAergic interneurons in the hippocampus following various types of injury. ${ }^{65-68}$ There also is evidence that severe injuries induce changes in the total number of interneurons and in specific populations of interneurons in the cortex. ${ }^{69}$ However, alterations in the cortical inhibitory circuit after mild injury have not been previously evaluated. The mild injury employed here does not induce overall changes in the total number of interneurons or number of interneurons that reside in different layers of the cortex shortly after injury or as a delayed mechanism at later post-injury time-points. Moreover, there was no change in the number of calretinin ${ }^{+}$interneurons at any of the post-injury time-points analyzed. However, we cannot discount the other populations of interneurons were differentially altered. Our investigations did reveal significant changes in calretinin ${ }^{+}$neurite plasticity and potential changes in GABAergic activity.

Previous studies have indicated that cortical GABAergic interneurons have the capacity to remodel their dendritic arbors under physiologically normal and pathological conditions. ${ }^{20,24,27,28}$ There is evidence indicating that interneurons are more plastic than pyramidal neurons. It has been reported that interneurons exhibit dynamic arbor rearrangements in the adult visual cortex while pyramidal neurons remain stable. ${ }^{27,28}$ Moreover, our previous experiments using a focal stab injury to the somatosensory cortex have found differences in post-injury structural plasticity between calretinin $^{+}$interneurons and pyramidal neurons. ${ }^{20}$ To first probe the cell type specific potential for neuroplasticity, an in vitro model of axonal injury was utilized. Using neurons derived from the transgenic mouse strains Thy1-YFP and GAD67-GFP that express fluorescent proteins in cortical pyramidal and inhibitory neurons, respectively. Analysis of post-injury neurite angle indicated that calretinin ${ }^{+}$interneurons reorientate their processes towards the intact neuropil, while there were no changes found in pyramidal neurons. The direct mechanisms for this cell type specific plasticity are unclear. After injury there is an important release of neurotransmitters, neurotrophic factors, and calcium. ${ }^{70,71}$ Given that remodeling was found to be restricted to an area close to the injury site and at an early post-injury time-point, it is plausible that the release of these diffusible factors around an injury site might have differential effects on specific cell types mediating neurite remodeling on calretinin ${ }^{+}$interneurons. Further, it is important ot note that the in vivo environment affords a unique post-injury environment that is not completely replicated in vitro. These results support the hypothesis that there are intrinsic differences in the neuronal response to injury between different neuronal subtypes and indicate that the remodeling of interneurons may play an important role after injury.

Using an in vivo model of injury, our studies demonstrate that sub-population specific morphological changes of calretinin ${ }^{+}$interneurons occur transiently in response to mild injury. At 7 days post-injury, calretinin ${ }^{+}$interneurons in the injury site had fewer secondary and tertiary processes when compared to the contralateral cortex and sham animals. While the changes in dendrite complexity are small, given the calretinin interneuron's unique connectivity and placement in the circuitry that enables significant control over inhibitory regulation as a whole, relatively small changes have the potential to elicit functionally significant effects. There was no significant reduction in the mean number of secondary order dendrites between the contralateral and ipsilateral sides after FPI. This could be due to the potential wide-reaching effects of the injury and provides evidence as to why the contralateral side is not an appropriate control. The changes in dendritic arbor complexity were time dependent and were restored to sham levels by 28 days post-injury. This transient response, observed both in vitro and in vivo, is indicative of a response of these interneurons to potential changes in either the extracellular environment or changes in intrinsic network connections occurring as a result of the injury; however, these mechanisms were not the focus of this current study. The vulnerability of calretinin ${ }^{+}$interneurons, in the form of loss and reorganization, has been described in animal 
models of ischemia and epilepsy. ${ }^{37,38}$ Previous studies indicate that in the naïve brain dendritic branch tip remodeling of interneurons in the adult visual cortex is mainly contained within a superficial strip of layer II/III of the cortex. ${ }^{27}$ Moreover, it has been reported that dendritic remodeling of GABAergic interneurons is not determined by genetic lineage but rather is a general feature of all interneuron subtypes imposed only by cortical laminar circuitry. ${ }^{24,27,28} \mathrm{Al}-$ though these previous elegant studies have indicated that there are no subtype specific differences in the capacity of structural remodeling in interneurons, results in our studies point to a cell type specific effect rather than laminar specific.

Functional studies were carried out to determine if the morphological changes found in the subpopulation of calretinin ${ }^{+}$interneurons after mild injury corresponded to functional alterations to the whole inhibitory circuit. Recordings of the inhibitory activity or inhibitory afferents onto pyramidal neurons were used as an indication of the overall inhibitory network activity after injury. ${ }^{69,72}$ To investigate this, mIPSCs were recorded from layer V pyramidal neurons within the injury site. mIPSCs are spontaneously occurring events that reflect spontaneous non-action potential-dependent release of single vesicles of GABA from individual pre-synaptic terminals of GABAergic interneurons. ${ }^{73}$ Results indicated that at 7 days post-injury the average amplitude of the mIPSCs was equivalent between sham and FPI-injured mice. The equivalent mIPSCs amplitude found between groups suggests that the expression of $\mathrm{GABA}_{\mathrm{A}}$ receptors in layer $\mathrm{V}$ pyramidal neurons after injury was likely unaffected. Mild TBI was associated with a significant decrease in mIPSCs frequency. The observed decrease in mIPSCs frequency indicates that the number of inhibitory connections onto layer $\mathrm{V}$ pyramidal neurons in the injured cortex was potentially decreased at 7 days post-injury. Given that there were differences found between the sham and FPI groups in mIPSCs frequency but not mIPSCs amplitude, these results suggest that changes in inhibitory synapses onto layer $\mathrm{V}$ pyramidal neurons are predominantly pre-synaptic rather than post-synaptic, reflecting changes in the inhibitory network. Moreover, there were no changes in mIPSCs kinetics (rise and decay time) indicating no changes in $\mathrm{GABA}_{\mathrm{A}}$ receptor-subunit composition in the post-synaptic neuron, further pointing to pre-synaptic involvement. ${ }^{74,75}$ Similar results have been reported for granule cells and pyramidal neurons in the hippocampus after both mild and severe brain injury at similar post-injury time-points. ${ }^{65,66,68}$ Either a decrease in the number or efficacy of inhibitory synaptic afferents onto the excitatory cells or a decrease in neurotransmitter release probability from these afferents, or a combination of both mechanisms could produce a decrease in mIPSC frequency. The synchronization of dendritic inhibitory cells is a crucial process to provide effective inhibitory control of excitatory synaptic input of pyramidal cell dendrites. ${ }^{37}$ As a result, calretinin ${ }^{+}$interneurons have a far-reaching and wide influence on the whole cortical inhibitory circuit. ${ }^{38}$ It is therefore hypothesized, while not directly tested, that the postinjury dendritic remodeling of calretinin ${ }^{+}$interneurons, in terms of loss of secondary and tertiary processes, could result in less effective synchronization of dendritic inhibitory interneuron firing, leading to less effective inhibition of pyramidal neuron firing and ultimately resulting in a pathologic shift toward excess excitability.

The current studies demonstrate that calretinin ${ }^{+}$interneurons undergo a cell type-specific response to injury both in vitro and in vivo resulting in significant dendritic remodeling. Importantly, these studies indicate that the structural alterations to calretinin ${ }^{+}$ interneurons observed correlate to functional changes in inhibitory input that may contribute to the cognitive impairment that can manifest following even seemingly mild forms of brain trauma. Targeting these inhibitory neurons after injury could potentially improve functional deficits found as a result of mild TBI.

\section{Acknowledgments}

GAD67-GFP mice were developed by Prof. Nobuaki Tamamaki (Kyoto University) and were provided by Prof. John Bekkers (Australian National University). This work was support by the National Health and Medical Research Foundation, the Tasmanian Masonic Medical Research Foundation, the Rebecca L. Cooper Medical Research Foundation and the Clive and Vera Ramaciotti Foundation.

\section{Author Disclosure Statement}

No competing financial interests exist.

\section{References}

1. Fortune, N. and Wen, X. (1999). The definition, incidence and prevalence of acquired brain injury in Australia. AIHW cat. no. DIS 15. Australian Institute of Health and Welfare: Canberra, Australia.

2. Blennow, K., Hardy, J., and Zetterberg, H. (2012). The neuropathology and neurobiology of traumatic brain injury. Neuron 76, 886-899.

3. Sullivan, K.A., Kempe, C.B., Edmed, S.L., and Bonanno, G.A. (2016) Resilience and other possible outcomes after mild traumatic brain injury: a systematic review. Neuropsychol. Rev.

4. Roozenbeek, B., Maas, A.I., and Menon, D.K. (2013). Changing patterns in the epidemiology of traumatic brain injury. Nat. Rev. Neurol. 9, 231-236.

5. McAllister, T.W., Flashman, L.A., McDonald, B.C., and Saykin, A.J. (2006). Mechanisms of working memory dysfunction after mild and moderate TBI: evidence from functional MRI and neurogenetics. J. Neurotrauma 23, 1450-1467.

6. Kennedy, J.E., Jaffee, M.S., Leskin, G.A., Stokes, J.W., Leal, F.O., and Fitzpatrick, P.J. (2007). Posttraumatic stress disorder and posttraumatic stress disorder-like symptoms and mild traumatic brain injury. J. Rehabil. Res. Dev. 44, 895-920.

7. Xydakis, M.S., Robbins, A.S., and Grant, G.A. (2008). Mild traumatic brain injury in U.S. soldiers returning from Iraq. N. Engl. J. Med. 358, 2177.

8. Vasterling, J.J., Verfaellie, M., and Sullivan, K.D. (2009). Mild traumatic brain injury and posttraumatic stress disorder in returning veterans: perspectives from cognitive neuroscience. Clin. Psychol. Rev. 29, 674-684.

9. Combs, H.L., Berry, D.T., Pape, T., Babcock-Parziale, J., Smith, B Schleenbaker, R., Shandera-Ochsner, A., Harp, J.P., and High, W.M. Jr. (2015). The effects of mild traumatic brain injury, post-traumatic stress disorder, and combined mild traumatic brain injury/posttraumatic stress disorder on returning veterans. J. Neurotrauma 32 , 956-966.

10. Keyvani, K. and Schallert, T. (2002). Plasticity-associated molecula and structural events in the injured brain. J. Neuropathol. Exp. Neurol. $61,831-840$

11. Chuckowree, J.A., Dickson, T.C., and Vickers, J.C. (2004). Intrinsic regenerative ability of mature CNS neurons. Neuroscientist 10 , 280-285.

12. Carmichael, S.T. (2006). Cellular and molecular mechanisms of neural repair after stroke: making waves. Ann. Neurol. 59, 735-742.

13. Dancause, N. and Nudo, R.J. (2011). Shaping plasticity to enhance recovery after injury. Prog. Brain Res. 192, 273-295.

14. Hunt, R.F., Scheff, S.W., and Smith, B.N. (2011). Synaptic reorganization of inhibitory hilar interneuron circuitry after traumatic brain injury in mice. J. Neurosci. 31, 6880-6890.

15. Canty, A.J., Huang, L., Jackson, J.S., Little, G.E., Knott, G., Maco, B., and De Paola, V. (2013). In-vivo single neuron axotomy triggers axon regeneration to restore synaptic density in specific cortical circuits. Nat. Commun. 4

16. Perederiy, J.V. and Westbrook, G.L. (2013). Structural plasticity in the dentate gyrus- revisiting a classic injury model. Front. Neural Circuits 7,17 . 
17. Horner, P. and Gage, F. (2000). Regenerating the damaged central nervous system. Nature 2000 407, 963-970.

18. Chen, R., Cohen, L.G., and Hallett, M. (2002). Nervous system reorganization following injury. Neuroscience 111, 761-773.

19. Cafferty, W.B., McGee, A.W., and Strittmatter, S.M. (2008). Axonal growth therapeutics: regeneration or sprouting or plasticity? Trends Neurosci. 31, 215-220.

20. Blizzard, C.A., Chuckowree, J.A., King, A.E., Hosie, K.A., McCormack, G.H., Chapman, J.A., Vickers, J.C., and Dickson, T.C. (2011). Focal damage to the adult rat neocortex induces wound healing accompanied by axonal sprouting and dendritic structural plasticity. Cereb. Cortex 21, 281-291.

21. Hensch, T.K. (2005). Critical period plasticity in local cortical circuits. Nat. Rev. Neurosci. 6, 877-888.

22. Di Cristo, G., Chattopadhyaya, B., Kuhlman, S.J., Fu, Y., Belanger, M.C., Wu, C.Z., Rutishauser, U., Maffei, L., and Huang, Z.J. (2007). Activity-dependent PSA expression regulates inhibitory maturation and onset of critical period plasticity. Nat. Neurosci. 10, 1569-1577.

23. Baroncelli, L., Braschi, C., Spolidoro, M., Begenisic, T., Maffei, L., and Sale, A. (2011). Brain plasticity and disease: a matter of inhibition. Neural Plast. 2011, 286073.

24. Chen, J.L., Flanders, G.H., Lee, W.C., Lin, W.C., and Nedivi, E. (2011). Inhibitory dendrite dynamics as a general feature of the adult cortical microcircuit. J. Neurosci. 31, 12437-12443.

25. Trachtenberg, J.T., Chen, B.E., Knott, G.W., Feng, G., Sanes, J.R., Welker, E., and Svoboda, K. (2002). Long-term in vivo imaging of experience-dependent synaptic plasticity in adult cortex. Nature 420 , 788-794.

26. Mizrahi, A. and Katz, L.C. (2003). Dendritic stability in the adult olfactory bulb. Nat. Neurosci. 6, 1201-1207.

27. Lee, W.C., Huang, H., Feng, G., Sanes, J.R., Brown, E.N., So, P.T., and Nedivi, E. (2006). Dynamic remodeling of dendritic arbors in GABAergic interneurons of adult visual cortex. PLoS Biol. 4, 271280.

28. Lee, W.C., Chen, J.L., Huang, H., Leslie, J.H., Amitai, Y., So, P.T., and Nedivi, E. (2008). A dynamic zone defines interneuron remodeling in the adult neocortex. Proc. Natl. Acad. Sci. U. S. A. 105, 19968-19973.

29. Yazaki-Sugiyama, Y., Kang, S., Cateau, H., Fukai, T., and Hensch, T.K. (2009). Bidirectional plasticity in fast-spiking GABA circuits by visual experience. Nature 462, 218-221.

30. Marik, S.A., Yamahachi, H., McManus, J.N.J., Szabo, G., and Gilbert, C.D. (2010). Axonal dynamics of excitatory and inhibitory neurons in somatosensory cortex. PLoS Biol. 8.

31. Keck, T., Scheuss, V., Jacobsen, R.I., Wierenga, C.J., Eysel, U.T., Bonhoeffer, T., and Hubener, M. (2011). Loss of sensory input causes rapid structural changes of inhibitory neurons in adult mouse visual cortex. Neuron 71, 869-882.

32. Chen, J.L. and Nedivi, E. (2013). Highly specific structural plasticity of inhibitory circuits in the adult neocortex. Neuroscientist 19 , 384-393.

33. Markram, H., Toledo-Rodriguez, M., Wang, Y., Gupta, A., Silberberg, G., and Wu, C. (2004). Interneurons of the neocortical inhibitory system. Nat. Rev. Neurosci. 5, 793-807.

34. Dzaja, D., Hladnik, A., Bicanic, I., Bakovic, M., and Petanjek, Z. (2014). Neocortical calretinin neurons in primates: increase in proportion and microcircuitry structure. Front. Neuroanat. 8, 103.

35. Barinka, F., Magloczky, Z., and Zecevic, N. (2015). Editorial: At the top of the interneuronal pyramid-calretinin expressing cortical interneurons. Front. Neuroanat. 9, 108.

36. Caputi, A., Rozov, A., Blatow, M., and Monyer, H. (2009). Two calretinin-positive GABAergic cell types in layer $2 / 3$ of the mouse neocortex provide different forms of inhibition. Cereb. Cortex 19, 1345-1359.

37. Toth, K. and Magloczky, Z. (2014). The vulnerability of calretinincontaining hippocampal interneurons to temporal lobe epilepsy. Front. Neuroanat. 8, 100

38. Toth, K., Eross, L., Vajda, J., Halasz, P., Freund, T.F., and Magloczky, Z. (2010). Loss and reorganization of calretinin-containing interneurons in the epileptic human hippocampus. Brain 133, 2763-2777.

39. Tamamaki, N., Yanagawa, Y., Tomioka, R., Miyazaki, J., Obata, K., and Kaneko, T. (2003). Green fluorescent protein expression and colocalization with calretinin, parvalbumin, and somatostatin in the GAD67-GFP knock-in mouse. J. Comp. Neurol. 467, 60-79.
40. Suzuki, N. and Bekkers, J.M. (2010). Distinctive classes of GABAergic interneurons provide layer-specific phasic inhibition in the anterior piriform cortex. Cereb. Cortex 20, 2971-2984.

41. Blizzard, C.A., King, A.E., Vickers, J., and Dickson, T. (2013). Cortical murine neurons lacking the neurofilament light chain protein have an attenuated response to injury in vitro. J. Neurotrauma. 30, 1908-1918.

42. Clarke, L.E., Young, K.M., Hamilton, N.B., Li, H., Richardson, W.D., and Attwell, D. (2012). Properties and fate of oligodendrocyte progenitor cells in the corpus callosum, motor cortex, and piriform cortex of the mouse. J. Neurosci. 32, 8173-8185.

43. Young, N.A., Flaherty, D.K., Airey, D.C., Varlan, P., Aworunse, F., Kaas, J.H., and Collins, C.E. (2012). Use of flow cytometry for highthroughput cell population estimates in brain tissue. Front. Neuroanat. $6,27$.

44. King, A.E., Southam, K.A., Dittmann, J., and Vickers, J.C. (2013). Excitotoxin-induced caspase-3 activation and microtubule disintegration in axons is inhibited by taxol. Acta Neuropathol. Commun. 1, 59.

45. Alder, J., Fujioka, W., Lifshitz, J., Crockett, D.P., and Thakker-Varia, S. (2011). Lateral fluid percussion: model of traumatic brain injury in mice. J. Vis. Exp. pii, 3063

46. Arciniegas, D.B., Anderson, C.A., Topkoff, J., and McAllister, T.W. (2005). Mild traumatic brain injury: a neuropsychiatric approach to diagnosis, evaluation, and treatment. Neuropsychiatric Dis. Treat. 1, 311-327.

47. Dewan, M.C., Mummareddy, N., Wellons, J.C., 3rd, and Bonfield, C.M. (2016). Epidemiology of global pediatric traumatic brain injury: qualitative review. World Neurosurg. 91, 497-509.e1.

48. Albrecht, M.A., Masters, C.L., Ames, D., and Foster, J.K. (2016). Impact of mild head Injury on neuropsychological performance in healthy older adults: longitudinal assessment in the AIBL cohort. Front. Aging Neurosci. 8, 105.

49. Girgis, F., Pace, J., Sweet, J., and Miller, J.P. (2016). Hippocampal neurophysiologic changes after mild traumatic brain injury and potential neuromodulation treatment approaches. Front. Syst. Neurosci. 10,8 .

50. Li, W., Risacher, S.L., McAllister, T.W., and Saykin, A.J. (2016) Traumatic brain injury and age at onset of cognitive impairment in older adults. J. Neurol. 263, 1280-1285.

51. Macias, M. (2008). Injury induced dendritic plasticity in the mature central nervous system. Acta Neurobiol. Exp. (Wars.) 68, 334-346.

52. Thompson, H.J., Lifshitz, J., Marklund, N., Grady, M.S., Graham, D.I., Hovda, D.A., and McIntosh, T.K. (2005). Lateral fluid percussion brain injury: a 15-year review and evaluation. J. Neurotrauma 22, 42-75.

53. Dixon, C.E., Lyeth, B.G., Povlishock, J.T., Findling, R.L., Hamm, R.J., Marmarou, A., Young, H.F., and Hayes, R.L. (1987). A fluid percussion model of experimental brain injury in the rat. J. Neurosurg. 67, 110-119.

54. Hayes, R.L., Stalhammar, D., Povlishock, J.T., Allen, A.M., Galinat, B.J., Becker, D.P., and Stonnington, H.H. (1987). A new model of concussive brain injury in the cat produced by extradural fluid volume loading: II. Physiological and neuropathological observations. Brain Inj. 1, 93-112.

55. Pitkanen, A. and Immonen, R. (2014). Epilepsy related to traumatic brain injury. Neurotherapeutics 11, 286-296.

56. Peterson, T.C., Maass, W.R., Anderson, J.R., Anderson, G.D., and Hoane, M.R. (2015). A behavioral and histological comparison of fluid percussion injury and controlled cortical impact injury to the rat sensorimotor cortex. Behav. Brain Res. 294, 254-263.

57. Ostergard, T., Sweet, J., Kusyk, D., Herring, E., and Miller, J. (2016) Animal models of post-traumatic epilepsy. J. Neurosci. Methods 272, 50-55.

58. Carbonell, W.S. and Grady, M.S. (1999). Regional and temporal characterization of neuronal, glial, and axonal response after traumatic brain injury in the mouse. Acta Neuropathol. 98, 396-406.

59. Dash, P.K., Mach, S.A., and Moore, A.N. (2001). Enhanced neurogenesis in the rodent hippocampus following traumatic brain injury. $\mathbf{J}$. Neurosci. Res. 63, 313-319.

60. Rice, A.C., Khaldi, A., Harvey, H.B., Salman, N.J., White, F., Fillmore, H., and Bullock, M.R. (2003). Proliferation and neuronal differentiation of mitotically active cells following traumatic brain injury. Exp. Neurol. 183, 406-417.

61. Blaiss, C.A., Yu, T.S., Zhang, G., Chen, J., Dimchev, G., Parada, L.F., Powell, C.M., and Kernie, S.G. (2011). Temporally specified genetic 
ablation of neurogenesis impairs cognitive recovery after traumatic brain injury. J. Neurosci. 31, 4906-4916.

62. Cope, E.C., Morris, D.R., Gower-Winter, S.D., Brownstein, N.C., and Levenson, C.W. (2016). Effect of zinc supplementation on neurona precursor proliferation in the rat hippocampus after traumatic brain injury. Exp. Neurol. 279, 96-103.

63. Wang, X., Gao, X., Michalski, S., Zhao, S., and Chen, J. (2016) Traumatic Brain Injury Severity Affects Neurogenesis in Adult Mouse Hippocampus. J. Neurotrauma 33, 721-733.

64. Salman, H., Ghosh, P., and Kernie, S.G. (2004). Subventricular zone neural stem cells remodel the brain following traumatic injury in adult mice. J. Neurotrauma 21, 283-292.

65. Witgen, B.M., Lifshitz, J., Smith, M.L., Schwarzbach, E., Liang, S.L., Grady, M.S., and Cohen, A.S. (2005). Regional hippocampal alteration associated with cognitive deficit following experimental brain injury: a systems, network and cellular evaluation. Neuroscience 133, $1-15$.

66. Mtchedlishvili, Z., Lepsveridze, E., Xu, H., Kharlamov, E.A., Lu, B., and Kelly, K.M. (2010). Increase of GABAA receptor-mediated tonic inhibition in dentate granule cells after traumatic brain injury. Neurobiol. Dis. 38, 464-475.

67. Pavlov, I., Huusko, N., Drexel, M., Kirchmair, E., Sperk, G., Pitkanen, A., and Walker, M.C. (2011). Progressive loss of phasic, but not tonic, GABAA receptor-mediated inhibition in dentate granule cells in a model of post-traumatic epilepsy in rats. Neuroscience 194, 208-219.

68. Almeida-Suhett, C.P., Prager, E.M., Pidoplichko, V., Figueiredo, T.H., Marini, A.M., Li, Z., Eiden, L.E., and Braga, M.F. (2015). GABAergic interneuronal loss and reduced inhibitory synaptic transmission in the hippocampal CA1 region after mild traumatic brain injury. Exp. Neurol. 273, 11-23.

69. Cantu, D., Walker, K., Andresen, L., Taylor-Weiner, A., Hampton, D. Tesco, G., and Dulla, C.G. (2015). Traumatic brain injury increases cortical Gglutamate network activity by compromising GABAergic Control. Cereb. Cortex 25, 2306-2320.

70. Weber J.T., Rzigalinski B.A., and Ellis E.F. (2001). Traumatic injury of cortical neurons causes changes in intracellular calcium stores and capacitative calcium influx. J. Biol. Chem. 276, 1800-1807

71. Morrison B., 3rd, Elkin B.S., Dolle J.P., and Yarmush M.L. (2011) In vitro models of traumatic brain injury. Annu. Rev. Biomed. Eng. 13, 91-126.

72. Smith C.J., Xiong G., Elkind J.A., Putnam B., and Cohen A.S. (2015). Brain injury impairs working memory and prefrontal circuit function. Front. Neurol. 6, 240.

73. Cohen, A.S., Pfister, B.J., Schwarzbach, E., Grady, M.S., Goforth P.B., and Satin, L.S. (2007). Injury-induced alterations in CNS electrophysiology. Prog. Brain Res. 161, 143-169.

74. Hollrigel, G.S. and Soltesz, I. (1997). Slow kinetics of miniature IPSCs during early postnatal development in granule cells of the dentate gyrus. J. Neurosci. 17, 5119-5128.

75. Banerjee, A., Garcia-Oscos, F., Roychowdhury, S., Galindo, L.C., Hall, S., Kilgard, M.P., and Atzori, M. (2013). Impairment of cortical GABAergic synaptic transmission in an environmental rat model of autism. Int. J. Neuropsychopharmacol. 16, 1309-1318.

Address correspondence to:

Tracey Dickson, BscHons PhD

Menzies Institute for Medical Research

University of Tasmania

Private Bag 23

Hobart 7000, Tasmania, Australia

E-mail: Tracey.Dickson@utas.edu.au 